\title{
NAS TESSITURAS DA EMERGENTE LITERATURA ROMANI (CIGANA): SUBALTERNIDADE, GÊNERO E IDENTIDADE EM QUESTÃO
}

\section{Paula Soria $^{1}$}

Resumo: Esse texto almeja discutir a literatura romani como um lugar de desconstrução: da identidade étnica "violada", da masculinidade hegemônica interna e da dupla subalternização da romi (cigana).

Palavras-chave: Literatura romani; subalternidade; gênero; identidade.

Abstract: This text aims to discuss Romani literature as a place of deconstruction: of an ethnics identity undergoing violence, of the internal male hegemoni and the double subaltenrnization of the romi (gipsy woman).

Keywords: Romani literature; subalternity; gender; identity.

Os movimentos de resgate de grupos que foram histórica e socialmente subalternizados pelas sociedades dominantes advêm, ordinalmente, de um processo de ressignificação e revalorização de sua identidade. Nesse sentido, a emergente literatura romani (cigana) contemporânea traz impregnada aos seus textos, um significativo ímpeto por afirmação, (re) construção identitária e novas configurações sociais, tanto interculturais quanto internas ao grupo. Apesar dessa escrita não estar atrelada ao movimento ativista rom (cigano), nem ser de nenhuma forma panfletária - os escritores romá (ciganos) atuais, de uma forma geral, conseguem produzir textos com um fundo afirmativo e social sem perder em literariedade - apresenta-se em consonância espontânea com o momento de "despertar étnico" que envolve o povo rom. Tal consciência política surge entre os grupos a partir do Primeiro Congresso Romani

\footnotetext{
${ }^{1}$ Doutora e mestra em Literatura pela Universidade de Brasília - UNB.Email:voripaula@yahoo.com.br
} 
Internacional, realizado em Londres em 1971, protagonizado pelas minorias ativas, ocasião na qual se institui símbolos unificadores, além da nova denominação romà, em substituição ao apelativo "ciganos", termo que não corresponde a uma autodenominação e, ao longo do tempo, foi sendo acrescido de uma pesada carga pejorativa ${ }^{2}$.

Os romà, em poucas palavras, e não entrando nos detalhes da complexa diversidade que envolve os distintos grupos, se constituem em uma minoria étnica presente em todos os países, com tradição e história comuns que os caracteriza como uma nação transnacional, que não possui nem pleiteia território. Possuem uma língua mãe comum, o romaní, que se desmembrou em distintas variações dialetais e chegou a ser perdida por alguns grupos ${ }^{3}$. Em consequência do hábito da fuga por intolerância das sociedades, o nomadismo foi introduzido como prática cultural. Atualmente, com a maioria já sedentarizada, os romà costumam ainda praticar um nomadismo circular. De cultura tradicionalmente oral, eles se negaram à escolarização e ao letramento como forma de evitar a aculturação e o convívio (ainda mais) estreito com os preconceitos. Ainda hoje, grande parte dos romà se mantêm na oralidade ou retira suas crianças e jovens, sobretudo as mulheres, precocemente das instituições de ensino formal. ${ }^{4}$

Ao contrário dos romà, conhece-se bastante os "ciganos", ou seja, os estereótipos negativos, exotizados e até sobrenaturalizados, histórica e ideologicamente imputados a toda uma minoria. Imagens difundidas à exaustão nas mais variadas representações sociais, sobretudo as artísticas e, especialmente, as literárias. Essa violência representacional se naturalizou e, sem questionamentos, se entranhou no imaginário social, encarcerando os

${ }^{2}$ Internamente se reconhecem pelos nomes dos três grupos que constitui a etnia: rom, sinti e calé ou calóns (como se denominam no Brasil e Portugal) e suas subdivisões em clãs e grupos familiares. Existe controvérsia interna sobre o uso político de "romà" sob a alegação de que privilegia o grupo rom. Porém, é indiscutível - e solicitado pela Unión Romani Internacional - URI - a importância do uso da nova denominação pela qual foram reconhecidos pela Unesco em 1982 como uma Nação transnacional e a ONU concedeu a URI, caráter consultivo. O termo gipsy, que originou variações em outras línguas provém de uma interpretação errônea por partes das sociedades, de que o grupo era proveniente do Egito. Já "ciganos" se originou da associação do grupo a antiga seita herética atsiganoi.

${ }^{3}$ Os romà foram escravizados na Romênia até 1864. A perda da língua foi uma das sequelas da longa escravidão.

${ }^{4}$ De acordo com dados divulgado pela Codeplan em maio de $2016,80 \%$ dos romà no Brasil possuem ensino fundamental incompleto ou nenhuma instrução, esta última correspondendo a $41.5 \%$. Cf Codeplan, "Invisibilidade e preconceito: um estudo exploratório dos ciganos no Distrito Federal", 2016, p.15.

|22| Revista Eletrônica Literatura e Autoritarismo, № 27 - janeiro a junho de 2016 - ISSN 1679-849X http://cascavel.ufsm.br/revistas/ojs-2.2.2/index.php/LA/index 
romà em uma "prisão de imagens" que auxiliou a mantê-los subalternizados. Essa dinâmica explicável, porém perversa, contribuiu substancialmente, tanto para a história ininterrupta de perseguição que culminou com o Porrajmos (holocausto rom) e para o que hoje se chama, principalmente na Europa, de ciganofobia generalizada, que contudo é um problema mundial que só varia de matiz, indo do racismo declarado ao sutil e do preconceito aberto ao velado.

Além de perseguidos, os romà foram "sequestrados" da historia das sociedades majoritárias ${ }^{5}$. Eles foram invizibilizados e silenciados enquanto tratavam de conservar a identidade por meio de estratégias que construíram uma identidade reativa e segregada. Aos romà foi imputado o lugar de "párias", que de acordo com Hannah Arendt, vai além da precariedade material imposta aos excluídos, caracterizando-se pela amputação pessoal e social de não poder "aparecer" no espaço público. Condição contrária a de cidadão, o que leva ao comum desinteresse pelos assuntos políticos, pois os romà não compartilham de um mundo comum com as sociedades ${ }^{6}$. Esta condição leva à "acomodação" em uma identidade de extrema resistência. De acordo com Manuel Castells, a identidade de resistência é criada pelos atores em condições subalternizadoras pela lógica de dominação, e pela própria condição de exclusão na qual são geradas, tendendo à essencialização e se tornando excludente. Mas é o próprio teórico que indaga sobre quem verdadeiramente constrói estas identidades e para quem, uma vez que são construídas em contextos marcados pelas relações de poder ${ }^{7}$. Uma identidade de resistência pode ser mantida ou se transformar em uma identidade de projeto, esta que se caracteriza por ser arquitetada pelos próprios atores sociais no sentido de reconstruir sua posição na sociedade, podendo, inclusive, efetivar transformações na própria estrutura social”" ${ }^{\prime \prime}$ os escritores romà contemporâneos inserem nos seus textos, discussões e reflexões que sugerem a construção e difusão de alicerces para essa transformação.

\footnotetext{
${ }^{5}$ Apesar de terem chegado à Europa Ocidental entre os séculos XIV e XV, sendo que no Brasil, surgem no século XVI, degredados de Portugal.

${ }^{6}{ }^{6} \mathrm{Cf}$. Los orígenes del totalitarismo. 2004 e ARENDT, Hannah. Escritos judíos. Barcelona: Paidós, 2009. Observa-se que o uso do termo, tanto pela filósofa como nesse artigo, não está relacionado ao sistema de casta indiano.

${ }^{7}$ O poder da identidade. 2008, pp.23- 26.

${ }^{8}$ Ibid,,pp.23-24. .
} 
O surgimento de uma literatura escrita divide o coletivo étnico, pois as "sequelas da história" levam boa parte do grupo a temer que o dar-se a conhecer os torne vulneráveis ao "outro" ameaçador. A escrita ainda é temida para um povo de pensamento baseado na oralidade. Leis, decretos e pragmáticas contra os romà foram ditados por ela, estereótipos irreais foram difundidos. E escrever na língua do "outro", utilizando as ferramentas e suportes das maiorias dominantes suscita a recorrente pergunta: é resistência ou submissão? Em primeiro lugar, os escritores romà sabem que se escreverem em sua língua mãe, reduzirão o alcance de suas obras, o que não é interessante, pois a proposta é de inclusão da literatura romani em um contexto não guetizado. Sabe-se ainda que o submeter-se a linguagem do dominante é uma condição comum imposta à escrita de minorias. Cíntia Schwantes, em relação à escrita feminina afirma que para ser entendida "ela precisará utilizar a linguagem masculina. [...] negociar no estreito espaço entre o apagamento e a possibilidade de representação" ". Considerando estas colocações, a emergência da literatura romani não é resistência, nem submissão, é o inicio de uma (re)construção.

É tornar-se sujeito de suas narrativas a partir de um discurso próprio, mesmo que não ausente de "ruídos" O reconhecimento implicado em poder falar é mais significativo do que o que advêm da atitude "tolerante" ao diferente. Nesse sentido, Júlia Kristeva propõe uma política do reconhecimento fundamentada, principalmente, em nossas ambivalências morais e necessidades pessoais como "sujeitos parlantes"10. A literatura romani, a que nomeio como um emergente e simbólico "território escrito" dos romà, se apresenta desterritorializada, nômade e transnacional, contemplando identificações com o passado romani e o futuro proposto pelas minorias ativas e "novos romà". Lugar propício para a desconstrução da subalternidade, um território contornado por vozes.

\footnotetext{
9 SCHWANTES, Cíntia. "Espelho de Vênus: questões da representação do feminino". Disponível em: < http://www.amulhernaliteratura.ufsc.br/artigo cintia.htm

${ }^{10}$ Extranjeros para nosotros mismos, 1991, pp. 153-154.
} 


\section{A (re)construção de gênero nos textos}

Existe um modelo de "bom rom" que é moldado na figura masculina do "velho de respeito" e na honra do pai de família. O respeito é adquirido com a maturidade, porém atrelado a um processo social contínuo de avaliação sobre a forma de proceder. Teresa San Román sintetiza este modelo como: uma forte ideologia de propriedade dos homens sobre as mulheres e seus filhos, uma androcracia consistente, a priorização das relações entre homens na construção da vida social e a autoridade última paterna, características que nomeia como uma ideologia machista e traumática ${ }^{11}$. A sociedade romani se rege por princípios patriarcais e sexistas, onde os papeis de gênero são bastante delimitados. No romance Maldito Gitano (1970) do escritor rom canadense Ronald Lee, por exemplo, o patriarca lembra a Kolia sobre o seu "papel": "[...] você já está muito velho para ficar só. Necessita de uma mulher que faça a sua comida, arrume sua roupa e me dê netos. Quase todos os romà se casam antes de ter cabelo no peito"12. Sua fala também deixa claro o "papel" da romi (mulher), tradicionalmente destinada ao casamento, aos filhos e a atender as demandas do marido e dos homens da comunidade. No seguinte trecho do romance autobiográfico El alma de los parias (2014), do escritor rom argentino Jorge Nedich, uma das personagens explica que já "pensa diferente", pois manda sua filha à escola: "mas às vezes falta, porque sai com a mãe para adivinhar a sorte, a menina é cigana, eu não posso educá-la muito, porque os ciganos não vão gostar dela [...] no fundo quero que esteja preparada porque se não se casa com um dos nossos, vai ser com um sedentário" ${ }^{13}$. A dificuldade de mudança efetiva em relação ao papel dos gêneros é grande, pois desde um ponto de vista de boa parte dos romà, o machismo - entendido por muitos, não como machismo, mas como traço cultural - não é "politicamente incorreto", nem motivo de vergonha. É uma forma de respeito à honra do coletivo e de proteção à romi.

\footnotetext{
${ }^{11}$ La diferencia inquietante. Viejas y nuevas estrategias culturales de los gitanos, 1997, p. 87.

${ }^{12}$ P. 42, "Eres demasiado mayor para vivir solo. Necesitas una mujer que te haga la comida, te arregle la ropa y me dé nietos a mí. Casi todos los Roms se casan antes de tener pelo en el pecho", Todas as traduções desse artigo são minhas.

${ }^{13}$ P.140. "pero a veces falta porque sale con la madre a adivinar la suerte, la piba es gitana, yo no la puedo educar mucho porque los gitanos no la van a querer [...] en el fondo quiero que esté preparada porque si no se casa con uno de los nuestros, lo hará con un sedentario",
}

Revista Eletrônica Literatura e Autoritarismo: Narrativa Testemunhal e Relações Históricas - ISSN 1679-849X | 25| http://cascavel.ufsm.br/revistas/ojs-2.2.2/index.php/LA/index 
A condição atual das mulheres romani - embora não possa ser generalizada, porque sofre variações relacionadas ao país em que vivem, à classe social, ao maior ou menor acesso aos estudos e ao grau de conservadorismo ou mudanças efetivada pelos grupos ou famílias - é de uma violência triple: a primeira é dividida com todas as mulheres e se insere nas questões de desigualdades de gênero mais amplas e no machismo que também impera nas sociedades majoritárias. Problema que é eclipsado pela violência do sexismo interno e pela violência advinda da subalternização imposta pelas sociedades, que mesmo sendo direcionada à etnia como um todo, pesa muito mais sobre a "cigana". A romi está mais exposta ao "outro", pois carrega as insígnias do grupo nas vestimentas, nos adornos e nos ofícios estigmatizados como a quiromancia. Dessa forma ela é a mais estigmatizada tanto nos contatos interétnicos como nas representações culturais.

É desde o próprio hibridismo cultural que os escritores romà contemporâneos trazem, entre outras "estratégias" de (re)construção observáveis ${ }^{14}$, as questões relacionadas ao gênero e especificamente à mulher romani. Chamo de híbrido cultural ao individuo "traduzido" que efetivou negociações culturais entre os "dois mundos" e terminou por habitar um "entre lugar". A tradução cultural, de acordo com Bhabha, difere e vai além da adaptação, porque é um processo no qual as culturas são impelidas a revisarem seus sistemas de referência e regras naturalizadas. Nesse processo, a ambivalência e o antagonismo acompanham o ato de tradução cultural, tendo em vista que, negociar com a diferença do outro traz à tona a insuficiência dos sistemas cristalizados de sentidos, além de evidenciar inadequações de "estruturas de sentimento", que fazem com que experimentemos nossa cultura como se fosse a mais "natural"

É a partir da desnaturalização de alguns costumes secularmente praticados que o híbrido Stieva, em El alma de los parias, explica criticamente ao filho mestiço sobre os problemas enfrentados pela mulher em seu grupo. Ao contar sobre o ritual do casamento, evidencia a existência de uma

${ }^{14}$ Outras estratégias de reconstrução identificadas na literatura romani são: subversão dos estereótipos e introjeções, a presença de personagens híbridos nos textos, o resgate da memória, do pensamento mágico e da oralidade e a construção de uma história social dos romà.

${ }^{15}$ The Vernacular Cosmopolitan", 2000, p. 141.

|26| Revista Eletrônica Literatura e Autoritarismo, oo 27 - janeiro a junho de 2016 - ISSN 1679-849X http://cascavel.ufsm.br/revistas/ojs-2.2.2/index.php/LA/index 
teatralização, a qual corresponde de que a noiva, geralmente bastante jovem, chore abertamente durante parte da cerimônia, que consiste em representar que ela está sendo roubada pela madrinha, que a entregará ao noivo. Enquanto narra o ritual, o narrador faz pequenas intrusões, nas quais comenta sobre a situação submetida da mulher dentro do grupo. Segundo ele, o choro "fingido" possui algo de real e o ritual traz à tona a realidade social. As meninas sabem que logo após o casamento devem viver e "servir" na casa de seus sogros. Stieva comenta que até meados do século $\mathrm{XX}$, o matrimônio era de um forte servilismo para a mulher "[...] e podia se direcionar a um modo de escravidão [...] o pagamento do dote outorgava direitos que desumanizavam a relação matrimonial e familiar da nova integrante. [...] a situação das mulheres melhorou, ainda que continuem sendo maltratadas em maior ou menor grau"16.

Por sua vez, o protagonista híbrido do romance Couleur de fumée: une épopée tzigane (1986), do escritor rom húngaro Menyhért Lakatos, faz uma avaliação crítica do sistema que o "beneficia" como homem, mas não the agrada. O protagonista se encontra absorvido em seus pensamentos a respeito da situação das mulheres que, segundo seu raciocínio, eram obrigadas a seguir estritamente uma espécie de "dez mandamentos" não escritos das romi casadas, dos quais ele explícita alguns, como verdadeiras interdições que fixam os privilégios dos homens face aos deveres das esposas: "Não seja preguiçosa, senão seu marido te deixará. Honre seu marido, ele é o chefe. Não discuta com seu marido, não tente ter a razão, pois ele é o homem. Não seja ciumenta"17. O jovem híbrido, de fato, não entendia (embora o soubesse) porque as mulheres não se rebelavam contra tal condição. O protagonista é retirado de seus questionamentos, quando a romi Rilyândri, surpreendida por saber que o jovem que a observava calado e pensativo, sabia escrever, aproxima-se e entrega-Ihe um lápis umedecido, para que marque em seu corpo algumas palavras: "- Amanhã de manhã eu vou tatuar isso. - Em cigano ou

\footnotetext{
${ }^{16} \mathrm{NEDICH}$, Jorge. El alma de los parias, p. 105. "[...] y podía encaminarse hacia un modo de esclavitud [...] el pago de la dote otorgaba derechos que deshumanizaban la relación matrimonial y familiar de la nueva integrante. [...] ha mejorado la situación de las mujeres, aunque todavía siguen siendo maltratadas en mayor o menor medida",

${ }^{17}$ P. 184." [...] Ne sois pas paresseuse, sinon ton mari se lassera. Honore ton mari, il est ton chef. Ne discute pas avec ton mari, n'essaie pas d'avoir raison, car c'est lui l'homme. $\mathrm{Ne}$ sois pas jalouse [...]".
} 
húngaro? - Em cigano, claro"18. Considerando a dimensão simbólica do corpo feminino para os romà, a tatuagem composta por "letras e palavras" - e não desenhos - desejada pela romi, indica a vontade de querer inscrever em seu "território corporal", o poder de mudar seu destino. No entanto, percebe-se que Rilyândri não quer romper, ela quer escrever em "cigano", utilizar as letras de sua tatuagem para renovar-se e fortalecer sua identidade. A personagem expressa um desejo frequentemente declarado pelas atuais romi ativistas.

\section{Tecendo novas masculinidades}

As questões sobre a subalternidade da romi se imbricam à desconstrução da masculinidade baseada no modelo hegemônico, que é tanto ou mais enfocada pelos escritores que a conscientização da própria mulher ${ }^{19}$. Em El alma de los parias, ainda nas páginas iniciais, o narrador declara 0 machismo rom dificilmente assumido quando diz ao filho criado entre não-romà que "nossos homens rebolam quando caminham, usam o cabelo comprido, gostam de cores e até de motivos femininos, e contraditoriamente, são muito mais machistas que os teus" ${ }^{\prime 20}$. O narrador considera que sua masculinidade, distinta do modelo rom, foi construída paulatinamente e entre "altos e baixos". Conta ao filho que as primeiras brigas em função das diferenças que surgiram, aconteceram quando a comunidade percebeu a influência que ele exercia nas irmãs que, ao contrário dele, mantinham-se na oralidade e eram criadas para seguir as tradições, "os adultos viam em nós uns pequenos traidores" ${ }^{21}$. Os conflitos acirram-se à medida que Stieva decide questionar os costumes, os quais eram considerados leis imutáveis.

${ }^{18}$ LAKATOS, Menyhért. Couleur de fumée, p. 184. "Demain matin, je le ferai tatouer. - En tsigane ou en hongrois? En tsigane, bien Sûr".

${ }^{19}$ Nesse sentido os textos escritos por escritoras romani, trazem diferenças significativas e complementárias. Elas parecem escrever mais para outras mulheres e trazer, com mais intensidade, a subjetividade desta condição de sentir-se subalternizada. A desconstrução de gênero na escrita feminina romani é um tema complementar, porem muito amplo para as dimensões desse artigo.

${ }^{20} \mathrm{NEDICH}$, Jorge, p.12. Internamente essa é uma afirmação polêmica, pois a voz romà quando assume o machismo, geralmente argumenta que não é maior que o machismo das sociedades não--romà, somente mais declarado. As romi ativistas e as que protagonizam mudanças nesses papeis em seus grupos, ainda lutam hoje por igualdade por direitos básicos, como poder desenvolver-se individualmente através do estudo e de um trabalho independente do coletivo. Observações feitas também em função do meu pertencimento ao grupo e vivencia como romi.

${ }^{21}$ Ibid., pp. 26-27. "[...] los adultos veían en nosotros a unos pequeños traidores".

|28 Revista Eletrônica Literatura e Autoritarismo, № 27 - janeiro a junho de 2016 - ISSN 1679-849X http://cascavel.ufsm.br/revistas/ojs-2.2.2/index.php/LA/index 
Quando Stieva deveria casar-se aos quinze anos, sugere que em lugar de juntar dinheiro para pagar o dote, que a família economizasse para comprar uma casa e deixar de morar dentro de uma barraca. A reação dos pais se situou entre a fúria de papu Ipe, que lhe deu uma forte bofetada e a tristeza mesclada a uma inexplicável sensação de liberação sentida pela mãe, a qual foi entendida por Stieva como se, por um lado, seu desalento se devesse ao fato de que ela desejava cumprir com as tradições, mas por outro lado, "o espírito de mamãe era transgressor"22 e, dessa forma, ela, uma mulher submetida às regras patriarcais, também se realizava ao ver o filho livrar-se das rígidas leis do grupo. Cada vez que algo assim acontecia, explica o narrador, "podíamos olhar o que havia atrás das pautas culturais [...]"23. Essa decisão acarretou em mudanças significativas no seu grupo familiar. Ao trocar o dote da esposa por uma casa, Stieva leva a família a abandonar os últimos resquícios do nomadismo, o que foi a garantia para um dia chegar a ser escritor. O casamento precoce não the permitiria, pois o obrigaria a seguir 0 "destino rom", segundo Stieva.

Faz parte desta desconstrução a discussão sobre a homossexualidade, evidenciando que não é uma "coisa" de gadyos (não-romà) nem uma doença adquirida, como pensa a personagem Rosa, mãe do narrador de El alma de los parias, que diariamente aconselhava seu filho a não falar como os "afeminados", porque ao fazê-lo, poderia se tornar um "degenerado"24. Já em Maldito gitano, a ênfase é evidenciar a existência de homossexuais romà e expor seus atuais conflito. Recorrentemente o narrador, Yanko, apresenta a personagem Kolia como um modelo de "verdadeiro rom", contudo Kolia guarda um segredo que é revelado no texto da seguinte forma: “- Você já sabe, Yanko, não é? - Sim, Kolia, compreendo, Você tentou. [...] Veja um homem como Charlie: ele gosta de mulheres, mas, o que ele é? Você trabalhou, obedeceu as leis, ajudou aos velhos e nunca fez mal a ninguém [...]"25. Kolia é um

\footnotetext{
22 Ibid., p. 20. "el espíritu de mamá era transgresor".

${ }^{23} \mathrm{NEDICH}$, Jorge. El alma de los parias, p. 20. "podíamos mirar qué había detrás de las pautas culturales [...]",

24 Ibid., p.75.

${ }^{25}$ LEE, Ronald, p. 265. "-Tú lo sabes, Yanko, ¿verdad? -Sí, Kolia, comprendo, Lo intentaste con Tinka, pero no salió bien. [...] Fíjate en un hombre como Charlie: a él le gustan las mujeres, pero ¿qué es él? Tú trabajaste, obedeciste tus leyes, ayudaste a los viejos y nunca hiciste daño a nadie.".
}

Revista Eletrônica Literatura e Autoritarismo: Narrativa Testemunhal e Relações Históricas - ISSN 1679-849X 
personagem que ao longo do romance vai se tronando progressivamente atormentado e taciturno: "ele se maldizia por ter quebrado algum preceito divino ou cigano" ${ }^{26}$. Ao ter sua homossexualidade declarada, escuta incrédulo as palavras de Yanko: "Ser homossexual "não é nenhum pecado, é só que os ciganos não compreendem estas coisas" ${ }^{27}$. Os leitores só descobrem a condição de Kolia após avançada mais da metade do romance e esta não abala a construção da personagem como um "bom rom". A revelação induz o leitor a reler as falas de Kolia considerando a subjetividade da sua condição.

O modelo masculino interno invisibiliza a homossexualidade e mantêm a subalternidade da romi, A falta de laços simbólicos com as sociedades circundantes, também é um fator agravante para a dificuldade de descontruir 0 sistema sexista. Os romà não encontram outro lugar para sua identidade se não no segregado círculo étnico. Promover rupturas com um modelo ao qual acreditam ter sido o sustentáculo da sobrevivência étnica gera o pavor do desaparecimento pela submersão em um mundo que não os inclui. Dessa forma, as (des)construções de gênero tecidas nos textos estão necessariamente imbricadas com a (re)construção identitária do coletivo étnico e a desconstrução do olhar estereotipador e preconceituoso das sociedades majoritárias em relação aos romà. A emergente literatura romani se configura como um espaço no qual a violência representacional e literária da qual foram objetos é subvertida, as sequelas reativas da "colonização interna" geradas pela história de estigmas e perseguição é discutida e o "algoz secular" representado e personificado na escrita é dominado e "convidado" a unir esforços em prol da reconstrução de uma identidade culturalmente rica e resistente que foi deteriorada pelos séculos de subjugação imposta.

\footnotetext{
${ }^{26}$ Maldito gitano, p.124. "Se maldecía a sí mismo por haber quebrantado algún precepto divino o gitano".

27 lbid., p. 265. "no es ningún pecado, es sólo que los gitanos no comprenden estas cosas". 


\section{Referências}

ARENDT, Hannah. Origens do totalitarismo. São Paulo: Companhia da Letras, 1990.

BHABHA, Homi K. “The Vernacular Cosmopolitan” In: DENNIS, F; KHAN, N.

(orgs). Voices of the Crossing. London: Serpent's Tail, 2000.

CASTELLS, Manuel. O poder da identidade. São Paulo: Paz e terra, 2008.

KRISTEVA, Júlia. Extranjeros para nosotros mismos. Esplugues de Llobrega: Plaza \& Janés, 1991

LAKATOS, Menyhért. Couleur de fumée: une épopée tzigane. Paris: Babel, 1986.

LEE, Ronald. Maldito gitano. Barcelona: Círculo de lectores, 1989.

NEDICH, Jorge. El alma de los parias. Buenos Aires: De la flor, 2014.

SAN ROMÁN, Teresa. La diferencia inquietante: viejas y nuevas estrategias culturales de los gitanos. Madrid: Siglo XXI de España, 1997.

SCHWANTES, Cíntia. "Espelho de Vênus: questões da representação do feminino". Disponível

em:

<http://www.amulhernaliteratura.ufsc.br/artigo_cintia.htm>

Acesso em: 16.4.2012. 